\title{
Factors Affecting Esophageal Varices Patients Compliance to Therapeutic Regimen and Suggested Guidelines
}

\author{
Amal Said Taha ${ }^{1}$, Manal Hamed Mahmoud ${ }^{2}$, Entsar Kamel Mohamed ${ }^{3}$ \\ ${ }^{1}$ Lecturer of Medical Surgical Nursing, Faculty of Nursing, Benha University, Egypt) \\ ${ }^{2}$ (Assistant Professor of Medical Surgical Nursing, Faculty of Nursing, Benha University, Egypt) \\ ${ }_{3}^{3}$ (Assistant Professor of Medical Surgical Nursing,Faculty of Nursing, Menofiya University, Egypt)
}

\begin{abstract}
:
Background: Acute bleeding from esophageal varices is repeatedly a remarkable event. The main goal of care is minimizing complications that affected by patient compliance to therapeutic regimen.

Aim of the study: Was to assess factors affecting esophageal varices patients' compliance to therapeutic regimen and suggested guidelines. Research design: A descriptive design utilized to carry out this study.

Sample: A convenient sample of 100 esophageal varices patients in GIT endoscopy unit and internal medicine units at Benha University Hospital over a period of six months. Tools for data collection: I) Interview schedule which include a) Socio demographic data sheet, b) Knowledge assessment sheet. II) Compliance assessment sheet to assess compliance of patients with esophageal varices to therapeutic regimen. III) Non-Compliance assessment sheet to assess factors affecting compliance of patients to therapeutic regimen. Results: revealed that majority of patients (68\%) of patients had unsatisfactory knowledge about disease and its therapeutic management. As well as, (61\%) of them had low level of compliance to therapeutic regimen. The most common factors affecting patients' compliance were, dyspnea(94\%), socio-economic factors(96\%) and uncooperative family(59\%) as well as having insomnia an feeling of worry(100\%). There was a significant statistical relation between compliance of the study group and their education, income and smoking.

Conclusion and Recommendations: In addition to non-compliance factors; the current study concluded that patients' compliance is affected by physical illness, socio-economic factors and psychological factors. Patients benefited from the given suggested guidelines, but further research is needed for developing interventions to improve compliance of EV patients.
\end{abstract}

Key words: Esophageal Varices, compliance, Therapeutic regimen.

\section{Introduction}

Rigorous variceal bleeding is a main cause of death in the emergency department and can be complex to treat. In general, upper (GI) bleeding records for 102 hospitalizations per 100,000 subject every year, and esophageal varices signify about $14 \%$ of these cases. In addition, esophageal varices are the widespread cause of constant and massive upper GI hemorrhage, representing about 33\% of these events. Amongst patients with cirrhosis, $70 \%$ of upper GI hemorrhage is caused by esophageal varices. Gasrto-esophageal varices exist in nearly $50 \%$ of patients with cirrhosis at the time of initial diagnosis (1).

In Egypt, it was anticipated that esophageal varices is the major cause of upper gastrointestinal bleeding, it grows in about 50-63\% of clients with liver cirrhosis, (2). The prevalence of upper gastrointestinal bleeding in Egypt is about 100 patients per 100.000 person per year. Hemorrhage from the upper gastrointestinal tract is around 4 times as common as bleeding from the lower GI tract (3).

The prognosis of clients with variceal hemorrhage is rigorous with a 6-week death rate of 20-30\%. Management for the prevention of re-bleeding from esophageal varices is very important. (4) and (5). Despite of considerable progress in mortality in the last 25 years, variceal hemorrhage still a fatal state that can be difficult to deal with in the emergency setting. Clues to management comprise identifying the poor prognosis and starting treatment rapidly, recognizing the key pharmacologic managements and organizing care timely with GI or surgical services as appropriate (6); (7); (8) and (9).

Compliance illustrates the extent to which a patient appropriately follows medical instructions. Usually, it refers to medication or drug compliance, but it can also relate to other condition such as medical appliance use, self-care, independent exercises, or treatment sessions. Both the patient and the health-care provider affect compliance, and a positive nurse-patient rapport is the most essential basis in enhancing compliance, while the high cost of medication also plays a main role (10).

Patient education is an essential aspect in enhancing compliance and can be seen as the base for the majority of patient-core intervention, education authorize patients to create decision about their treatment, and can develop their motivation and intent to comply with the therapeutic regimen as prescribed. Educational interventions concerning patients, their family members, or both can be useful in enchaining compliance. 
One of the nurse's tasks is to validate that patients comprehend the information they expected by request patients to replicate dosing directions and discussing the patients' potential for treatment. Collaborating the patient in the decision-making process about treatment may also raise patient motivation and enhance adherence (11).

\section{Significance of the Study:}

Esophageal variceal hemorrhage is the universal cause of acute upper gastrointestinal bleeding in Egypt. It incorporates a disastrous outcome of portal hypertension due to high incidence of schistosomiasis and viral hepatitis with high prevalence of morbidity and mortality regardless of recent therapeutic resources making a most important public health problem in Egypt. It represents for $75 \%$ of all upper gastrointestinal bleeding (UGIB) and accounts for $20 \%$ of deaths amongst Egyptian clients between the ages of 35 to 75 years, whilst in the Western countries it represents for $30 \%$ of all upper gastrointestinal bleeding (12), and (13).

As mentioned by (14), compliance is one of the most significant educational product in patient education to evaluate effectiveness of all teaching efforts. Therefore, nurse should establish education for patients with esophageal varices from the day of hospitalization for improving their compliance to therapeutic regimen. It's essential duty of the nurse to verify factors influencing compliance to therapeutic regimen among patients with esophageal varices to improve their outcomes.

Non Compliance of clients with (EV) to therapeutic regimen is a major dilemma for such groups, health specialists and health care organization. Moreover, non-compliance leading to raise morbidity and mortality, add to cost of treatment, deterioration of disease, more numerous physicians visits, raise hospitalization, death cost-effective impact, lost income and sick time (15). The nurse have significant role in identifying a problem of non-compliance, assessing factors of non-compliance amongst patients and implement certain interventions to manage these factors or adjust the suggested modifications(16). So this study carried out to assess factors affecting esophageal varices patients' compliance to therapeutic regimen and providing them with suggested guidelines.

\section{Aim of the study:}

This study aimed to assess factors affecting esophageal varices patients' compliance to therapeutic regimen and providing them with suggested guidelines.

\section{Research questions:}

To fulfill the aim of this study, the research questions were:

1. What do patients know about the esophageal varices?

2. What are the factors affecting esophageal varices patients' compliance to therapeutic regimen?

3. Is there any relation between patient compliance to therapeutic regimen and their socio-demographic characteristics?

\section{Research Design:}

\section{Subject And Methods}

\section{Variables of study:}

- The dependent variable is therapeutic regimen.

- The independent variable: factors affecting esophageal varices patients' compliance.

\section{Setting:}

The study was conducted at the gastrointestinal (GIT) endoscopy unit and internal medicine units at Benha University Hospital.

\section{Sample:}

A convenient sample of 100 adult male and female patients with esophageal varices admitted to gastrointestinal endoscopy and internal medicine units at Benha University Hospital.

\section{Inclusion criteria:}

* Adult patients, from both gender

* Conscious and able to communicate with others

* Diagnosed with esophageal varices with previous attacks of bleeding

* Patients free from physical \& mental handicapped

\section{Exclusion criteria:}

* Newly diagnosed esophageal varices patients

* Patients with physical or mental handicapped

* Comatose patients 
Tools of Data Collection:

I. Patients interview schedule: It constructed by investigators based on previous authors (17); (18) (19) it comprised of two parts:

A- Socio Demographic data sheet: Included information related to patients socio-demographic profile as age, sex, education level, residence, nature of work, income, history of disease.

B- Knowledge Assessment Sheet: It included 20 multiple choice questions about knowledge regarding esophageal varices, causes, aggravating factors , complications, and different management strategies.

Scoring system: For each item, a correct response scored 1 and the incorrect scored zero with total scores out of 20. The scores were summed-up and the total divided by the number of the items, giving a mean score for the part. These scores were converted into a percent score, and means and standard deviations were computed. Knowledge considered satisfactory if the percent score was $50 \%$ or more and unsatisfactory if less than $50 \%$.

II. Compliance Assessment Sheet: It was adapted from (20); (21); (22); (17) ; (18) \&(19) to assess compliance of esophageal varices patients to therapeutic regimen.It comprised (50 questions) including medication related factors (9items), diet related factors (14 items), exercise related factors (5 items) and follow-up regimen (22 items).

Scoring system: The items reported to be done scored " 1 " and the items not done were scored "0". For each area, the scores of items summed-up, while total divided by the number of the items, giving a mean score of the part. These scores were converted into a percent score. The compliance was considered adequate if the percent score was $60 \%$ or more and inadequate if less than $60 \%$.

III. Non Compliance Assessment Sheet: To assess factors affecting esophageal varices patients' compliance to therapeutic regimen. This part adapted by the investigators and modified based on review of recent literature (21); (17);(18);(19). It comprised (32 questions) including patient related factors (physical, social\& financial, psychological factors, patient's believes, and factors related to medical team).

Physical factors(4 questions): it included chest pain, fatigue, dyspnea, nausea and vomiting(answer was by yes/no)

- Social \& financial factors(7 questions): it included effect of disease on work and family and availability of income to deal properly with therapeutic needs (answer was by yes/no)

- Psychological factors (6 questions): it included presence of insomnia, feeling of crying, shame in front of others, feeling of low self-esteem, anxiety and depression with options of never, sometimes and always.

- Patients' believes(11 question): it included difficulties to be compliant, compliance leads to be more dependent on others, restricts and changes lifestyle, their trust in medical information, and face any problems in follow-up(answer was by yes/no)

- Medical team related factors(4 questions):It included medical team clearance, good medical team relation, medical team regulates follow-up programs suitable with your condition and medical team follow patient's compliance in each visit (answer was by yes/no)

Scoring system: all variables weighted (38 score) according to the items included in each question \{a question that implies response with (No) scored as "0", and (Yes) scored as "1"\} except for items related to psychological factors \{a question that implies response with (Never) scored as "0" while (Sometimes) scored as "1" and (Always) scored as "2"\}.

IIII. Suggested guidelines: These guidelines developed for purpose of supplying the patients with information about esophageal varices and how to comply with therapeutic regimens. The guidelines content included knowledge and instructions (i.e. definition of disease, patho-physiology of disease, signs and symptoms, complications of the disease, medication, diet, exercise and importance of follow up). These guidelines demonstrated by pictures and posters because $70 \%$ of the studied subjects were illiterate.

\section{Validity and reliability:}

Validity test was established for testing content of tools for comprehensiveness, relevance, simplicity, clarity and ambiguity through a jury of five experts in the field of \{nursing, and internal medicine $\}$ including one professor in medical surgical nursing, three assistant professors of medical surgical nursing and one lecturer in internal medicine at Benha University. Reliability of the instrument tested with Cronbach's Alpha (tool II) = 0.861 , which indicated the reliability of the tool. 


\section{Operational Design:}

\section{Ethical considerations:}

Informed oral consent was obtained from each patient before starting the data collection. Confidentiality was ensured throughout the study process, where personal data was not disclosed, and the patients were assured that all data will be used only for research purpose. The researcher emphasized that the participation is voluntary and they have the right to participate or not and to end the interview or withdraw without giving any reason at any time.

\section{Pilot Study:}

Pilot study conducted on (10\%) of patients with esophageal varices in two weeks before starting the study in order to test the clarity and applicability of the study tools and to estimate time needed for filling in the sheets as well as to identify any possible obstacles that may hinder data collection. According to the answers and comments of the patients, the researchers modified some of the questions. Patients involved in the pilot study were not included in the main study.

\section{Field work:}

Permissions for data collection generated from hospital directors and head managers of the GIT endoscopy and internal medicine units at Benha University Hospital and by the submission of a formal letters from the Faculty of Nursing, Benha University.

An exploratory visit was done to the GIT endoscopy unit and internal medicine units at Benha University Hospital in order to estimate the rate of admission and suitable time for collecting data. In addition, personal communication done with the nurses and physicians to explain the purpose of the study and gain their possible cooperation.

Data for the current study collected through the period from beginning of February 2016 till jully 2016. The estimated time spent with each patient for collecting data lasted between 20-30 minutes, and about 1 to 2 patients were interviewed daily, through 3 days/week during morning and afternoon shifts.

\section{Statistical Design:}

The collected data tabulated and statistically analyzed using Statistical Package for Social Science (SPSS), version 20 .Numerical data were expressed as mean and standard deviation. Qualitative data expressed as frequency and percentage. Chi-square test used to examine the relation between qualitative variables. Whenever the expected values in one or more of the cells in a $2 \times 2$ tables was less than 5, fisher exact test used instead. A significant level value was considered when $\mathrm{p}<0.05$.

\section{Limitations of the Study:}

- Unsuitable environment, there was too much noise, lack of privacy, intrusion of strangers....etc.

- Data obtained from the study can't be generalized because of limited number of patients.

\section{Results}

Table (1): showed that the majority (86\%) of the study subject's age ranged from (40-60) years old, with a mean age of $54.6 \pm 6.30$ years. Also, the majority $(86 \%, 87 \%$, respectively) of the study subjects was married and received insufficient income. The table also revealed that Less than three quarters of them $(74 \%, 70 \%, 70 \%$, respectively) were males, illiterate and had supply of medication on their own cost respectively. Concerning patient's occupation, more than half $(65 \%)$ of them were unemployed. Regarding residence, $75 \%$ of the study subjects lived in rural areas and $25 \%$ in urban areas.

Table (2): illustrated that, less than half of the studied sample (40\%) had bilhariziasis and kidney disease; more than half of them $(63 \% \& 60 \%)$ had hypertension and diabetes, while, all of them (100\%) had liver cirrhosis, bled from less than 1 year, received blood transfusion. Also, all of them (100\%) made endoscopy and near two thirds of them $(65 \%)$ repeated it more than once.

Table (3): demonstrates that the highest mean $(74 \pm 10.564,70 \pm 5.873 \& 69.25 \pm 6.609$, respectivelly) of the studied sample had incorrect knowledge regarding disease characteristics (definition of esophageal varices (EV), diagnosis of EV, causes of EV \& signs and symptoms of EV), complications of EV and medical regime

Figure (1): shows that two thirds of the studied group (68\%) had unsatisfactory knowledge, while, the minority of them $(32 \%)$ had satisfactory knowledge about esophageal varices.

Table (4): Illustrates that more than half $(61 \%)$ of the studied sample had inadequate level of compliance to therapeutic regimen for $\mathrm{EV}$ disease compared to $39 \%$ of them had adequate level of compliance. 
Table (5): shows that, the majority of the studied group having physical problems $(94,90$, and $85 \%$ ) as dyspnea, chest pain and fatigue respectively. Also, they had social and economic problems (100\%) due to that income is insufficient leading to defect in following diet regimen, follow-up program and buying drugs.

Table (6): displays that, the entire studied group (100\%, $100 \%$,) always had insomnia and feeling worry about their physical condition. Also, $(95 \%, 80 \%)$ sometimes had depression and unable to work, feeling with low self esteem, respectively. While ( $75 \%, 74 \%$ respectively) had feeling with shame in front of others, as well as had no desire to complete treatment.

Table (7): reveals that, the studied group (100\%) stated that therapeutic regimen is useful and complete compliance is difficult, leads to be dependent on others, and causes change in lifestyle. Moreover, they had problems with follow-up. In addition, the majority of them $(92 \%, 90 \%$ respectively) stated that relation with medical team was good and clear. While, $(80 \%)$ them said that medical team didn't follow patient's compliance in each visit.

Table (8): illustrated that there was a significant statistical relation between patient's compliance and their education $(\mathrm{P} \leq 0.05)$, as well as income and smoking $(\mathrm{P} \leq 0.01)$.

Table (1): Distribution of the studied sample according to their socio-demographic characteristics $(\mathrm{n}=100)$

\begin{tabular}{|c|c|c|c|}
\hline \multirow[b]{2}{*}{ Age } & $40-60$ & $>\mathbf{6 0} \quad f(\%)$ & Mea SD \\
\hline & $86(86.0)$ & $14(14.0)$ & $54.6 \pm 6.30 \mathrm{y}$ \\
\hline \multirow[b]{2}{*}{ Sex } & $f(\%)$ & Female $\quad f \quad(\%)$ & \\
\hline & $74(74.0)$ & $26(26.0)$ & \\
\hline \multirow[b]{2}{*}{ Education } & Illiterate & Literate $f(\%)$ & \\
\hline & $70(70.0)$ & $30 \quad(30.0)$ & \\
\hline \multirow[b]{2}{*}{ Occupation } & Unemployed $f(\%)$ & Employed $f(\%)$ & \\
\hline & $65(65.0)$ & $5 \quad(35.0)$ & \\
\hline \multirow[b]{2}{*}{ Residence } & Rural & Urban & \\
\hline & $75(75.0)$ & $25(25.0)$ & \\
\hline \multirow[b]{2}{*}{ Marital status } & Married & Unmarried $f(\%)$ & \\
\hline & $86(86)$ & $14(14.0)$ & \\
\hline \multirow[b]{2}{*}{ Income } & $\begin{array}{ll}\text { Sufficient } & f(\%) \\
\end{array}$ & Insufficient $f(\%)$ & \\
\hline & $13 \quad(13.0)$ & $87(87.0)$ & \\
\hline \multirow[t]{2}{*}{ Source of medication } & Health insur. $f(\%)$ & Own cost $f(\%)$ & \\
\hline & $30(30.0)$ & $70(70.0)$ & \\
\hline \multirow[b]{2}{*}{ Smoking } & $f(\%)$ & $f \quad(\%)$ & \\
\hline & $42 \quad(42.0)$ & $58 \quad(58.0)$ & \\
\hline
\end{tabular}

Table (2): Distribution of the studied sample according to their disease history $(n=100)$

\begin{tabular}{lcc}
\hline Disease history & N0 & \% \\
\hline * Disease complain: & 100 & 100.0 \\
\hline Liver cirrhosis & 63 & 63.0 \\
\hline Hypertension & 60 & 60.0 \\
\hline Diabetes & 40 & 40.0 \\
\hline Bilhariziasis & 40 & 40.0 \\
\hline Kidney disease & & 100.0 \\
\hline$*$ First bleeding attack from EV: & 100 & 36.0 \\
\hline$>1$ year & & 64.0 \\
\hline Frequency of bleeding from EV: & 36 & 100.0 \\
\hline Once & 64 & 100.0 \\
\hline More than one & 100 & 35.0 \\
\hline$*$ Blood transfusion & 100 & 65.0 \\
\hline$*$ Make endoscopy before & & 35 \\
\hline Once & 65 & \\
\hline More than one & & \\
\hline
\end{tabular}


Factors Affecting Esophageal Varices Patients Compliance To Therapeutic Regimen And Suggested

Table (3): Mean and standard deviation of the studied sample according to their knowledge about disease $(\mathbf{n}=\mathbf{1 0 0})$

\begin{tabular}{lcccc}
\hline & \multicolumn{2}{c}{ Correct answer } & \multicolumn{2}{c}{ Incorrect answer } \\
\cline { 2 - 5 } Knowledge Items & $\mathbf{X}^{\mathbf{2}}$ & $\mathbf{S D}$ & \multicolumn{1}{c}{$\mathbf{X}^{\mathbf{2}}$} & $\mathbf{S}$ \\
\hline Disease Characteristics & 26 & 10.564 & 74 & 10.564 \\
\hline Disease Complications & 30 & 5.873 & 70 & 5.873 \\
\hline Factors aggravating bleeding & 39.25 & 8.926 & 60.75 & 8.926 \\
\hline Medical regimen & 30.75 & 6.609 & 69.25 & 6.609 \\
\hline Dietary regimen & 38.666 & 2.624 & 61.333 & 2.624 \\
\hline
\end{tabular}

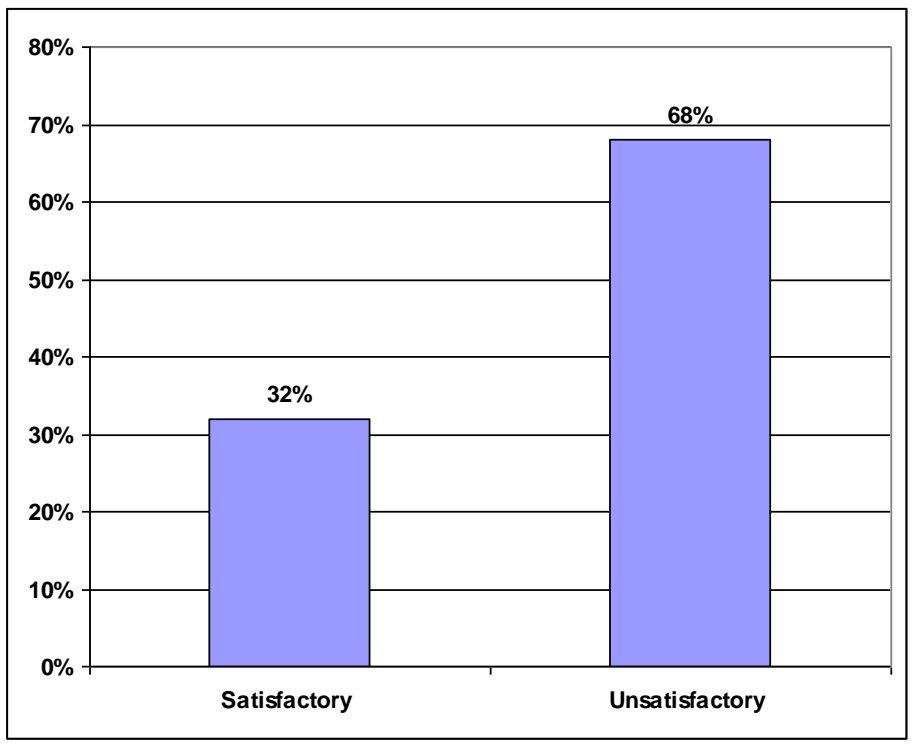

Fig.(1): Distribution of the studied group according to their total knowledge $(n=100)$

Table (4): Distribution of the studied sample according to their compliance to therapeutic $\operatorname{regimen}(n=100)$

\begin{tabular}{lcccc}
\hline \multirow{1}{*}{ Compliance Items } & Adequate & \multicolumn{2}{c}{ Inadequate } \\
\cline { 2 - 5 } & $\mathbf{N}$ & $\mathbf{\%}$ & $\mathbf{N}$ & $\mathbf{\%}$ \\
\hline Medication & 40 & 40.0 & 60 & 60.0 \\
\hline Diet & 38 & 38.0 & 62 & 62.0 \\
\hline Exercise & 36 & 36.0 & 64 & 64.0 \\
\hline Follow up & 42 & 42.0 & 58 & 58.0 \\
\hline Total Compliance & 39 & 39.0 & 61 & 61.0 \\
\hline
\end{tabular}

Table (5): percentage distribution of $f$ non-compliance factors related to physical and social problems

\begin{tabular}{|c|c|c|}
\hline Items & No & $\%$ \\
\hline \multicolumn{3}{|l|}{ * Having any physical problems: } \\
\hline Chest pain & 90 & 90.0 \\
\hline Fatigue and general weakness & 85 & 85.0 \\
\hline Dyspnea & 94 & 94.0 \\
\hline Nausea and vomiting & 40 & 40.0 \\
\hline \multicolumn{3}{|l|}{ *Social and economic factors } \\
\hline * Work style & 96 & 96.0 \\
\hline *Family cooperation & 95 & 95.0 \\
\hline * Income is insufficient & 100 & 100.0 \\
\hline \multicolumn{3}{|c|}{ * Insufficient income leads to defect in: } \\
\hline Diet regimen & 100 & 100.0 \\
\hline Follow-up program & 100 & 100.0 \\
\hline Buying drugs & 100 & 100.0 \\
\hline Practicing physical exercise & 0 & 0.0 \\
\hline
\end{tabular}


Table (6): percentage distribution of non-compliance factors related to psychological problems $(\mathrm{n}=100)$

\begin{tabular}{|c|c|c|c|c|c|c|}
\hline \multirow[t]{2}{*}{ Items } & \multicolumn{2}{|c|}{ Never (0) } & \multicolumn{2}{|c|}{ Sometimes (1) } & \multicolumn{2}{|c|}{ Always (2) } \\
\hline & No & $\%$ & No & $\%$ & No & $\%$ \\
\hline Having insomnia & 0 & 0.0 & 0 & 0.0 & 100 & 100.0 \\
\hline Feeling with shame in front of others & 25 & 25.0 & 75 & 75.0 & 0 & 0.0 \\
\hline Feeling with low self -esteem & 20 & 20.0 & 80 & 80.0 & 0 & 0.0 \\
\hline Feeling worry about physical condition & 0 & 0.0 & 0 & 0.0 & 100 & 100.0 \\
\hline Having no desire to complete treatment & 26 & 26.0 & 74 & 74.0 & 0 & 0.0 \\
\hline Having depression and unable to work & 5 & 5.0 & 95 & 95.0 & 0 & 0.0 \\
\hline
\end{tabular}

Table (7): percentage distribution of non-compliance factors related to medical team and patient believes $(n=100)$.

\begin{tabular}{lcc}
\hline \multicolumn{1}{c}{ Items } & No & \% \\
\hline$*$ Therapeutic regimen is useful & 100 & 100.0 \\
\hline$*$ Complete compliance is difficult & 100 & 100.0 \\
\hline$*$ Compliance leads to be dependent on others & 70 & 70.0 \\
\hline$*$ Compliance leads to change in lifestyle & 100 & 100.0 \\
\hline *Having problems with follow-up & 100 & 100.0 \\
\hline *If yes why? & 40 & \\
\hline Traffic problems & 50 & 40.0 \\
\hline Low income & 5 & 50.0 \\
\hline Laziness & 5 & \\
\hline physical exertion & 5.0 \\
\hline Medical team related factors: & 5.0 \\
\hline Medical team clearance & 90 & \\
\hline Good medical team relation & 92 & 90.0 \\
\hline Medical team regulates follow-up programs suitable with your condition & 45 \\
\hline Medical team follow patient's compliance in each visit & 20 \\
\hline
\end{tabular}

Table (8): Relation between patients' compliance and their socio-demographic characteristics

\begin{tabular}{|c|c|c|c|c|c|c|c|}
\hline \multicolumn{2}{|c|}{ Socio-demographic Items } & \multicolumn{2}{|c|}{ Adequate } & \multicolumn{2}{|c|}{ Inadequate } & \multirow[t]{2}{*}{ Chi -Square } & \multirow[t]{2}{*}{ P-value } \\
\hline & & $\mathbf{N}$ & $\%$ & $\mathbf{N}$ & $\%$ & & \\
\hline \multirow[t]{2}{*}{ Age(years) } & $40-60$ & 34 & 34.0 & 52 & 52.0 & 0.0734 & $>0.05$ \\
\hline & $>60$ & 5 & 5.0 & 9 & 9.0 & & \\
\hline \multirow[t]{2}{*}{ Sex } & Male & 34 & 34.0 & 40 & 40.0 & 1.006 & $>0.05$ \\
\hline & Female & 9 & 9.0 & 17 & 17.0 & & \\
\hline \multirow[t]{2}{*}{ Education } & Illiterate & 14 & 14.0 & 45 & 45.0 & 4.524 & $<0.05^{*}$ \\
\hline & Educated & 18 & 18.0 & 23 & 23.0 & & \\
\hline \multirow[t]{2}{*}{ Occupation } & Unemployed & 30 & 30.0 & 35 & 35.0 & 1.315 & $>0.05$ \\
\hline & Working & 12 & 12.0 & 23 & 23.0 & & \\
\hline \multirow[t]{2}{*}{ Residence } & Rural & 30 & 30.0 & 45 & 45.0 & 0.00 & $>0.05$ \\
\hline & Urban & 10 & 10.0 & 15 & 15.0 & & \\
\hline \multirow{2}{*}{$\begin{array}{c}\text { Marital } \\
\text { Status }\end{array}$} & Married & 35 & 35.0 & 51 & 51.0 & 0.743 & $>0.05$ \\
\hline & Unmarried & 4 & 4.0 & 10 & 10.0 & & \\
\hline \multirow[t]{2}{*}{ Income } & Sufficient & 15 & 15.0 & 8 & 8.0 & 7.242 & $<0.01 * *$ \\
\hline & Insufficient & 26 & 26.0 & 51 & 51.0 & & \\
\hline \multirow[t]{2}{*}{ Smoking } & Yes & 16 & 16.0 & 50 & 50.0 & 11.647 & $<0.01 * *$ \\
\hline & No & 20 & 20.0 & 14 & 14.0 & & \\
\hline
\end{tabular}

\section{Discussion}

The present study aimed firstly to assess factors affecting compliance of patients with esophageal varices to therapeutic regimen and secondly suggesting guidelines for the patient to improve their compliance to therapeutic regimen. Discussion the findings of this study will cover the main areas; demographic characteristics, patients' compliance to therapeutic regimen and factors affecting their compliance.

Regarding socio-demographic characteristics of the patients; the current study pointed out that the mean age of the sample was 54.6 \pm 6.30 years and Less than three quarters of them were males. This would be attributed to the fact that Egyptian males are responsible for farming work which may expose them to bilharizial infection and liver disease. These findings agreed with (23) in their study about "CT esophagography: Non invasive screening and grading of esophageal varices in cirrhosis" who found that three quarter of the subjects were male and their mean age was $56.84 \pm 7.52$ years. As well as (4) and (24) who found that bleeding esophageal varices were widespread in males and a mean age more than fifty years. However; these results were lower than those of (25), who reported in their study that, clients were mostly males and the average age was 49 years, while about, half of the sample size was between the ages of 45 and 54 years. In addition, (26), found the same result. 
Concerning the educational levels of the studied sample; the results showed that, nearly three quarters were illiterate. This would be attributed to the fact that the mainstream of the sample were from rural areas and working as farmers. This finding was supported by (12), who stated in her study that, about half of patients were illiterate, about one third were farmers and the greater part of patients were from rural areas. Also, she clarifies these results that farmers are more proned to schistosomal infection and its subsequent liver dysfunction and bleeding esophageal varices.

Regarding their marital status; the majority of the study subjects were married. And reported that income is insufficient especially the majority pays costs of medication on their own cost. This was in line with (27), who reported in a study about assessment of nurse's Knowledge and Practice toward Caring of Patient with gastrointestinal bleeding at Benha University Hospital, that the majority of patients under study were married. Also, the findings about family income are relevant with (12), who reported that the majority of the studied sample were farmers and had little financial resources, which indicate that they not have the expenses of medical treatment.

As regards to smoking; the present study revealed that more than half of the samples were previous smokers. This could be powered with the physicians' orders to stop smoking and the recurrent health education campaigns in the mass media about the effects and problems on body health as stated by patients themselves. These findings are inconsistent with (28) whose study revealed that the greater part of patients were smokers.

Concerning medical history; the present study results showed that, less than half of patients had kidney disease, all of them had liver cirrhosis and less than half had previous treatment of shistisomiasis. In a recent study by (29), explicated that, association of hepatitis c virus(HCV) with chronic kidney disease (CKD) is controversial, due, in part, to conflicting research findings. Although, HCV transmission in dialysis units has been well recognized, a high number of patients new admitted to dialysis already have HCV, signifying that the virus often is acquired before beginning dialysis therapy. Also, results from the third national health and nutrition examination ultrasound (US) survey conducted by (30), identified that, among a representative sample of the US population, hepatitis $\mathrm{C}$ is independently allied with albuminuria amongst adults over the age of 40 and HCV appears to be most frquently accompanied with membrano proliferative glomerulonephritis. As well as, (31) and (32),stated that the occurrence of HCV infection is elevated in clients on hemodialysis than in general population.

As regards first bleeding from esophageal varices; the entire sample reported that, the 1st bleeding was from less than one year and the majority stated that it occurred only one time. These findings were supported by (33), who reported that nearly half of patients with newly detected liver cirrhosis have associated varices every year, new varices are extend or the preexisting varices deteriorate in $7 \%$ of patients, and first bleeding occurs in $12 \%$ of clients each year.

In relation to blood transfusion; the entire sample mentioned that they received blood transfusion or its products. These findings supported by those of (34), who reported that treatment goals for acute variceal bleeding are to approve hypovolemia; attain fast hemostasis; and avoid early rebleeding. Also, he stated that the earliest step of treatment in clients with bleeding is the assessment of the severity of the bleeding, and the attainment of hemodynamic balance through providing sufficient fluids and transfusion.

Concerning patients' knowledge about esophageal varices; findings of the present study showed that two thirds of the studied group had unsatisfactory level of knowledge regarding esophageal varices and management. There are three possible reasons to explain the unsatisfactory knowledge level of this group of subjects. First, their formal education background may be a factor related to this unsatisfactory knowledge in which nearly three quarters were illiterate. This would be attributed to the lack of opportunity to be educated on esophageal varices prevention programs. Moreover, the lack of learning resources for nurses to up-date their knowledge about esophageal varices and prevention of its complications.

This finding supported with (35) who stated in a quasi-randomized controlled trial that newly discharged patients often have complications that lead to re-hospitalization. Many of these troubles are the result of inability to understand and sufficiently manage post discharge care needs. Also, suggested that the Patient program extensively improved patients' comprehension and knowledge of their diagnoses, treatment, and necessary follow-up care. Otherwise the nurse should communicate with clients and teach them about risk factors, life style adjustment related to all items of therapeutic regimen and the significance of compliance to prescribed regimen. This is consistent with (36) who stated that, the patient's confidence about the worth and advantage of a treatment for esophageal varices may progress obviously when compare with the priority given to the same treatment by the nurse.

Regarding compliance of patients' with esophageal varices to therapeutic regimen; The current study revealed that, more than half of the studied sample had inadequate compliance toward medication management and not complies with healthy diet. This could be attributed to lack of their knowledge regarding healthy diet regimen and the outcome of unhealthy habits. This was congruent with (37) who found no one of the studied patients compliant with their healthy diet.

DOI: 10.9790/1959-0603028898 $\quad$ www.iosrjournals.org $\quad 95 \mid$ Page


Despite the importance of exercises for healthy life, results of study showed more than half of patients were not practicing any type of exercise. This result might be due to level of education and lack of their knowledge regarding the significance of exercises to be accomplished and lack of ability of patients to carry out suitable physical exercise as result of physical problems. This finding is in line with what stated by (38), who reported that more than half of their studied patients were not comply to exercise which may be due to incapability to carry out exercise or not have knowledge about its importance.

The current study revealed that, more than half of study subjects had problems with their follow-up. This may be illustrated as the patients reported that reasons for not attending follow-up are traffic problems and lengthy space between home and hospital in which nearly three thirds of patients were from rural areas. In agreement with these findings (39), found that more than two thirds of patients didn't comply with follow-up regimen. Disagreement to these study findings was by (21), who reported that, more than half of the studied sample were adhere to medication, diet and follows up.

Regarding factors affecting patients' compliance to therapeutic regimen; as regard to the common physical factors that impede patients' compliance with therapeutic regimen, the current study revealed that the majority of patients reported that they have physical problems such as dyspnea, chest pain, fatigue and general weakness. These symptomatic problems may be due to effect of disease or drug side effects. This is in agreement with (40), who found that there is considerable relation between patients' physical state and their adherence with treatment. Moreover, (41) stated that, an essential but ignored symptom of HCV is fatigue. Fatigue is thought to blow on well-being and mood in patients with HCV, but this still to be fully recognized. Fatigue is partly overturned following treatment and the response rate is generally low. In addition, (42) stated that, greater part of HCV patients found physical, social and mental problems with antiviral treatment.

As regard to the common social factors that obstruct patients' compliance with therapeutic regimen, the current study revealed that that majority of patients had social and economic problems that hinder their compliance. This may be due to expenses of medication, long distance between hospital and home which leads to irregular attendance. The most important finding was that the majority of patients reported that the disease causes problems at work and also at home. This result is supported by (43), who found that economic support for patients enhanced their compliance. This is also similar to findings of (37) who found that patient who has inadequate financial resources or health insurance has inadequate adherence. These findings is also congruent with that stated by (44) who found out that drug expenses also present another obstacle to compliance with drug therapy, also, the high price of drug gaining can be an obstacle to adherence as mentioned by half of patients under study.

With reference to psychological factors that hinder patients' compliance with therapeutic regimen, the current study discovered that the whole group mentioned that they always had insomnia and felt worry about their physical condition. This could be attributed to the effect of the disease, recurrent attacks of bleeding, fear of death, change in work and overall lifestyle. This finding is supported by (13) and (38) who stated in their study that non-compliant patients emerge to have elevated incidence of stressful life proceedings. Noncompliance can't be exclusively explained by one aspect but rather may occupy an individual's health beliefs, emotional intelligence, psychological stressors, and personality character.

Regarding patients' believes about compliance to therapeutic regimen; the findings of the study revealed that, all patients consider therapeutic regimen more useful but it is difficult and needs more time and efforts. This is in line with (45), who found in their study that believes in relation extensively influence compliance levels. This is an essential finding as describing key beliefs; also, non-adherence was a problem among a part of the sample. This is inconsistent with (46), who found that the patients' view about therapeutic regimen was thorough, complicated, and has many compound limitations over a long time.

About relation to knowledge from medical team related factors that hinder patients' compliance with therapeutic regimen; the results of the current study revealed that, the patients under the study stated that the relation with medical team affects their compliance and there is a good medical team relation. This is supported by (47), who mentioned that patient care giver rapport is the main issue in patients' compliance to both medication regimen and therapeutic compliance treatment. Also, this is in line with (48) and(49) who stated that major obstacles to adherence are thought to include medication regimens, deprived health status and not have of treatment benefits. This is inconsistent with (50), who stated in her study that the greater part of clients mentioned that the relation with their physician and nurse don't influence their adherence and the nurse doesn't demonstrate the significance of compliance and side effects of non-compliance.

Regarding relation between patients' compliance to therapeutic regimen and their socio demographic characteristics; the present study demonstrated that a statistical significant relationship between patients' total compliance and socio-demographic characteristics as education,. This relation in the present study may be related to the fact that educational level increase in people's alertness about importance of following the prescribed regimen and what should be done to maintain or enhance their compliance. This findings agrees with (19) who studied "Effect of discharge planning for patients with esophageal varices on compliance to therapeutic regimen"; revealed that a statistical significant association between patients' total compliance and

DOI: 10.9790/1959-0603028898 www.iosrjournals.org $\quad 96 \mid$ Page


socio-demographic characteristics. In agreement with these findings (51) who illustrated that adherence to therapeutic regimen raises when they have better learning. These findings disagree with (52) who stated that there was no significant relation found between the educational level of the clients and their adherence with treatment.

The present study demonstrated that, there was a statistical significant relationship between patients' total compliance and socio-demographic characteristics such as income. This relation in the present study may be related to the fact that compliance improved with social support in the form of income and decrease with reduced social support. This may be due to the fact that social support helps patient in dropping negative attitudes towards treatment. This result was in agreement with (53), they mentioned that, there were statistically significant association between income and compliance.

The current study illustrated that a statistical significant relationship between patients' total compliance and socio-demographic characteristics such as smoking. This relation in the present study may be related to that more than half of the study subjects were previous smokers. This could be attributed with the physicians' strategy to stop smoking and the repeated health education campaigns in the mass media about the effects and complications of smoking. This result was in agreement with (54) and (55), who revealed that, only about one quarter of male patients were smokers.

\section{Conclusion And Recommendations}

It can be concluded from this study that more than half of patients with esophageal varices in the study setting have inadequate compliance and unsatisfactory knowledge regarding intervention of esophageal varices. Compliance is influenced by patients' socio-demographic data, characteristics of disease, barriers factors affecting compliance, as well as knowledge. The patients with low compliance had a high prevalence of complications, and recurrent esophageal bleeding. Therefore, patient compliance needs to be improved through providing teaching programs for EV patients and their families. Additionally, the barriers perceived by these patients need to be addressed, especially the physical barriers related to diet, exercise and knowledge. Further researches are needed to develop and refine interventions to improve compliance of patients with esophageal varices and to evaluate the impact of managing barriers factors on their compliance. Patients in this study benefited from the given booklet of suggested guidelines but they need establishing an educational program about therapeutic regimen in a further study.

[1]. American college of emergency physicians (2014): Focus on Variceal Hemorrhage, Available at: http://www. acep.org /Content aspx? id $=80193$ Accessed in October, $7 / 2014$.

[2]. Hosney Z. (2014): Evaluating the effect of designed implemented nurse'seducational program on minimizing incidence of complications for patients with upper gastrointestinal bleeding, doctorate thesis, medical-surgical nursing, faculty of nursing, Benha University, P.104.

[3]. Longstreth GF and Feitelberg SP. (2008): Successful outpatient management of acute upper gastrointestinal hemorrhage: use of practice guidelines in a large patient series. GastrointestEndosc, (3):219-22.

[4]. Hobolth, L., Krag, A. and Bendtsen, F. (2010):The recent reduction in mortality from bleeding oesophageal varices is primarily observed from Days 1 to 5. Liver Int; 30: 455-62.

[5]. Thiele, M., Krag, A., Rohde, U. and Gluud, L.L. (2012): Meta-analysis: banding ligation and medical interventions for the prevention of rebleeding from oesophagealvarices. Alimentary Pharmacology \& Therapeutics, 35: 1155-1165.

[6]. Cheung, J. (2009): Urgent Vs. Non-Urgent Endoscopy in Stable Acute Variceal Bleeding. Am J Gastroenterol.;104: 1125-9.

[7]. Sarin, N., Monga, N. and Adams, P.C. (2013): Time to endoscopy and outcomes in upper gastrointestinal bleeding. Can J Gastroenterol, 23(7):489-93.

[8]. Orloff , M.J. (2009): Randomized trial of emergency endoscopic sclerotherapy versus emergency portacaval shunt for acutely bleeding esophageal varices in cirrhosis. JACS; 209:25-40.

[9]. Garcia-Pagan, J. (2010): Early use of TIPS in patients with cirrhosis and variceal bleeding. N Engl J Med.; 362(25):2370-9.

[10]. Santschi, V., Chiolero, A. and Burnier, M. (2009): Electronic monitors of drug adherence: tools to make rational therapeutic decisions. Journal of hypertension; 27(11): 2294-5.

[11]. Jensen, .K.M., (2009): Obesity, Behavioral Lifestyle Factors and Risk of Acute Coronary Events, 8th Ed, Lippincott Williams and Wilkins, Philadelphia; Pp: 774-790.

[12]. Sallam, S.A. (2007):Compliance of patients with Esophageal Varices to Therapeutic Regimen. Unpublished Master Thesis, Faculty of Nursing. Menoufyia University.

[13]. Williams, L.S. and Hopper, P.D. (2012): Understanding Medical Surgical Nursing. (4th ed.). F.A.Davis. Philadelphia; P:786.

[14]. Gulanick M and Davis MN. (2009): Nursing Care Plans: Nursing diagnosis and Intervention. (6th ed.) Mosby El Seveir Co, Philadelaphia\& US; P:186.

[15]. Timby, C., (2010):Care of the Acutely Ill Adult, an Essential Guide for Nurses. (1st ed.) Oxford University Press, New York; Pp:60-67.

[16]. Carpenito, M. (2009): Nursing Care Plans and Documentation. Nursing Diagnosis and Collaborative Problems (5th Ed), Wolters Kluwer Lippincott Williams and Wilkins ., Tokyo; Pp: 36 \&655-665.

[17]. Ouf, H.Z., (2013):Factors Affecting Compliance of Patients with Angina Pectoris Toward Therapeutic Regimen.,। Master Thesis, Medical Surgical Nursing, Faculty of Nursing, Benha University.

[18]. Ramadan, S.T., (2013):Assessment of Renal Transplant Recipient's Needs at Urology and Nephrology Center. Master Thesis, Medical Surgical Nursing, Faculty of Nursing, Benha University.

[19]. Abou-El-Fadl, N.M.(2015):Effect of discharge planning for patients with esophageal varices on compliance to therapeutic regimen. Doctorate thesis, Faculty of Nursing, Benha University.

[20]. Mersal, M., (2008): Managing Heart Failure: A Case Study Approach. Critical Care Nurse; 21(2). 
[21]. Mohamed, R., (2008): Risk factors associated with Re-hospitalization of elderly patients suffering from heart failure. Master thesis, Faculty of Nursing, Alexandria University, Pp:75-80.

[22]. Carven, R.F., Hirnle, C.J., (2009): Fundamentals of Nursing, Human Health and Function, 6th Ed., Lippincott Williams and Wilkins, New York \& London, P:695.

[23]. Moftaha, S.H. G, Kamala, S. Hannab, A.T.K. (2014): CT esophagography: Noninvasive screening and grading of esophageal varices in cirrhosis. The Egyptian Journal of Radiology and Nuclear Medicine; 45,(2): 263-270.

[24]. Hassan, AY. (2012): Validation of P2/MS and other non-invasive indices for detecting esophageal varices in patients with liver cirrhosis. Unpublished Master Thesis.Faculty of medicine - Cairo University.

[25]. Davis, K.L., Mitra, D., Medjedovic, J., Beam, C., and Rustgi, V. (2011): Direct Economic Burden of Cirrhotic Hepatitis C Virus in A United States Managed Care Population. Journal of Clinical Gastroenterology; 45(2): e17-e24.

[26]. Heneedy, W. (2009): Relation between Confirmed Hepatitis C Virus and Shistosomiasis among School Children in Rural Area in Gharbieya Governorate. Egypt: Unpublished Doctorate Thesis in Nursing Science, Faculty Of Nursing, Menoufyia University. Pp: 1-30.

[27]. Mahmoud, E.A. (2013): Assessment of Nurse's Knowledge and Practice Toward Caring of Patient with Gastrointestinal Bleeding at Benha University Hospital, Unpublished Master Thesis, Medical Surgical Nursing, Faculty of Nursing, Benha University, Pp:15-30.

[28]. Golemon, C.L. and Sobiera, J. (2012): Effect of pharmacological therapies for stroke prevention or major gastrointestinal bleeding in patients with atrial fibrillation International Journal of Cinical Practice; 66(1).

[29]. Butt, A.A., Wang, X. and Fried, F.L. (2011): HCV Infection and the Incidence of CKD. Am J Kidney Dis; 57(3):396-402.

[30]. Tsui, J.I., Viittinghoff, E., Shlipak, M.G., and O’hare, A.M. (2006): Relationship Between Hepatitis C And Chronic Kidney Disease: Results From The Third National Health Nutrition Examination Survey. J Am SocNephrol; 17: 1168-1174.

[31]. Russo, M.W., Golgsweig, C.D., Jacobson, I.M. and Brown, R.S. (2009): Interferon Monotherapy for Dialysis Patients with Chronic Hepatitis C: An Analysis of Literature for Efficacy and Safety. Am J Gastroenterology; 98:1610-5.

[32]. Sarhan, A.E. (2011):Home Health Care Program for Patients with Hepatitis "C" Virus and their Family Members in Kalyubia Governorate. Unpublished Doctorate Thesis, Public Health Nursing, Faculty of Nursing, Benha University, Pp:92-101.

[33]. Kovalak, M., Lake, J., Mattek, N., Eisen, G., Lieberman, D. and Zaman. A. (2007): Endoscopic screening for varices in cirrhotic patients: data from a national endoscopic database. Gastrointest Endosc; 65:82-88.

[34]. Kim, Y.S. (2014): Surgical Duration and Risk of Venous Thromboembolism JAMA Surg; 10:18-41.

[35]. Barkun, A.N., Bardou, M. and Jincloir, P. (2010): International Consumers Upper Gastrointestinal Bleeding Conference, Group Recommendations on the Management of Patients with Non Variceal Upper Gastrointestinal Bleeding Annals of Internal Medicine; 152(2)

[36]. Runciman, L. (2007): Subjectively Perceived Quality of Life after esophageal varices. American Journal of Critical Care;11(3).

[37]. Mohamed, N.E. (2010): Effect of Counseling on Patients' Compliance with Therapeutic Regimen after Surgery, Unpublished Doctorate Thesis in Nursing Science. Faculty of Nursing, Ain Shams University.

[38]. Jin, J., Edward, G.S., Minv, S. and Chuen. S.L. (2008): Factors affecting therapeutic compliance: A review from the patient's perspective. There Clin Risk Manag; 4 (1): 269-86. Published online 2008 February, 2008.

[39]. Williams, J. (2007): Plaque Pathology And Coronary Thrombosis In The Pathogenesis of Acute Coronary Syndromes. Scandinavian Journal of Clinical and Laboratory Investigations;59 (230).

[40]. Gorin, D.K. (2010): Critical Care Nursing A Holistic Approach. (8th Ed.) Lippincott Williams \& Wilkins, NewYork; Pp: 469480 .

[41]. Mellors, D. and McInnes, L. (2011): Fatigue in HCV Infection: A Review (1989-2011) Adelaide, South Australia

[42]. Zickmund, S.L., Bryce, C.L., Blasiol, J.A. and Shinkunas, L. (2006): Majority with Patients of HCV Express Physical, Mental, and Social Difficulties with Antiviral Treatment. Eur J GastroenterolHepatol; 18(4): 381-388.

[43]. Bensinger, C.B. (2011): Home Care Patient and Family Instruction. (2nd Ed.) Saunders Company, Philadelphia; Pp: $23-42$.

[44]. Benjamin, R.S. (2012): Understanding Medical Surgical Nursing. (2nd Ed.) Davis Company, Philadelphia; Pp: $227-231$.

[45]. Walsh, K., and Kowanko, I. (2011):"Nurses' \& patients' perceptions of dignity". international journal of Nursing Practice; 8: 143-51.

[46]. Wealthy, N.K. (2012): Myocardial Infarction and Coronary Revascularization, Cardiology 1 Review; 117.

[47]. Darwish, M.A., Faris, R., \& Darwish, N., (2008): Hepatitis C and Cirrhotic Liver Disease in the Nile Delta of Egypt: A Community-Based Study. Am J Trop Med Hyg; 64(3-4): 147-53.

[48]. $\quad$ Elliott, R.A. and Marriott, J.L. (2009):"Standardized assessment of patients' capacity to manage medications: a systematic review of published instruments". BMC Geriatr; 9: 27.

[49]. Ngoh, L.N. (2009): "Health literacy: a barrier to pharmacist-patient communication and medication adherence". J Am Pharm Assoc ;49 (5): 132-149.

[50]. Gbre, W.F., (2013): Assess The Compliance of Patients with Coronary Artery Bypass Graft Toward Therapeutic Regimen, Unpublished Master thesis, Medical-Surgical Nursing Department, Faculty of Nursing, Benha Uiversity. Pp:97-104.

[51]. Penny, R., (2008): The Molecular and Cellular Pathophysiology of Heart Failure. Heart and Lung; 27.

[52]. Gnesdiloff, W.H. (2011): Mother's Compliance to pre-Discharge Plan .Effect on Heath of their Nephrotic Children .Doctorate thesis in Nursing Science. Faculty of Nursing, Tanta University.

[53]. Seo, M.A., Min, S.K. (2005): Development of a Structural Model Explaining Medication Compliance of Persons with Schizophrenia. Yonsei Med J;46:331-40.

[54]. Patterson, J. (2007): Off-Pump Versus Conventional Coronary Artery Bypass Grafting. Early and 1-Year graft patency, cost and quality of life outcomes. Journal of the American Medical Association;1841.

[55]. Ahamed, N. (2009): Compliance Of Hypertensive Elderly Patients With The Treatment Regimen, Master Thesis, Faculty Of Nursing, Alexandrai University, Pp:85-93. 